\title{
Noxious or Non-noxious Inputs to Oxytocin Neurons: Possible Roles in the Control of Behaviors
}

\author{
Tatsushi ONAKA*, Shota OKABE, Yuki TAKAYANAGI, and Masahide YOSHIDA \\ Division of Brain and Neurophysiology, Department of Physiology, Jichi Medical University, \\ Shimotsuke, Tochigi 329-0498, Japan
}

Received July 9, 2015; final version accepted July 27, 2015

\begin{abstract}
Oxytocin plays an essential role in milk ejection and parturition in mammals. Oxytocin has also been shown to be involved in the control of various behaviors, including anxiety-related behaviors, food intake and affiliative behaviors.

We previously showed that noxious stimuli or stimuli previously paired with noxious stimuli (conditioned fear stimuli) activate hypothalamic oxytocin neurons via activation of brainstem catecholaminergic/prolactin-releasing peptide (PrRP)-positive neurons. Oxytocin neurons are activated not only by noxious stimuli but also by nonnoxious touch stimuli. Social contact has been suggested to activate oxytocin neurons. Non-noxious tactile stimuli induce $50-\mathrm{kHz}$ ultrasonic vocalization, an index of positive states in rats, and activate hypothalamic oxytocin neurons, suggesting that pleasant tactile stimuli activate oxytocin neurons.

Physiological roles of oxytocin released during noxious or non-noxious tactile stimuli remain to be clarified. Noxious stimuli increase anxiety-related behavior, while pleasant sensory stimuli have pro-social actions. We have shown that endogenous oxytocin reduces anxiety-related behaviors, induces a decrease in amounts of food intake per meal, and facilitates social recognition via distinct neural pathways. Roles of oxytocin released during sensory stimuli may be dependent upon the sensory stimuli used, and oxytocin may contribute to the prevention of overreactions to noxious stimuli or mediate pro-social or anxiolytic actions of pleasant tactile stimuli.
\end{abstract}

KEYWORDS: oxytocin, noxious stimuli, conditioned fear, pleasant touch, ultrasonic vocalization

\section{Introduction}

In mammals, oxytocin is mainly synthesized in the hypothalamus and released from the neurohypophysis, and it facilitates parturition or lactation in females. However, oxytocin is synthesized and released into the peripheral circulation not only in females but also in males. Furthermore, oxytocin is an evolutionarily conserved peptide, and oxytocin or its homologs are expressed not only in mammals but also in non-mammal vertebrates including agnathans, fishes and amphibians [18,37]. Some kinds of insects, snails and nematodes also express oxytocin homologs. It is thus easy to speculate that oxytocin has functions other than parturition or lactation. In fact, C. elegans, which has a long evolutionary distance from mammals, expresses the homolog of oxytocin named nematocin $[4,22]$. Nematocin has been shown to be required for normal sexual behaviors of males and for salt-chemotaxis-related behaviors [5]. These findings suggest that sexual behavior and salt homeostasis are fundamental roles of oxytocin and its related peptides.

In mammals, the neurohypophysis releases oxytocin and its closely related peptide vasopressin. Oxytocin and vasopressin differ by only two amino acids. Genes for these two peptides have the same structures (three exons and two introns) and are located adjacently on the same chromosome in opposite transcriptional directions. Thus, the oxytocin and vasopressin genes are considered to have derived from a gene duplication that occurred approximately 450 million years ago. Oxytocin and vasopressin are synthesized in distinct neurons located in the magnocellular regions of the paraventricular and supraoptic nuclei in the hypothalamus and are released into the peripheral blood stream from the neurohypophysis, to which oxytocin- or vasopressin-synthesizing neurons project. Oxytocin is also synthesized in neurons located in the parvocellular region of the paraventricular nucleus of the hypothalamus or in the bed nucleus of stria terminals. These oxytocin neurons project to other brain regions $[36,37,49]$.

Considering that an oxytocin homolog plays an important role, across the evolutionarily diverse animal species, in normal reproductive behaviors, which are regrarded as prototypes of social behaviors, it is not surprising that in mammals that construct a complex society, oxytocin is involved not only in reproduction-related behaviors, including the formation of pair-bonding in monogamous species, sexual behavior, and parental behavior, but also in various other social behaviors such as social bonding among consociates. In mammals oxytocin has been shown to facilitate social memory, increase recognition of emotional expression, and mediate social buffering that reduces stress responses by 
being accompanied by mothers, partners or cage mates. Thus, it is possible that oxytocin facilitates not only finding and forming appropriate pairs, giving birth and nursing children but also establishing friendship and building and maintaining appropriate social relationships [10,17,34,59,68,76]. Oxytocin has been implicated in disorders associated with dysfunctional social behaviors, including autism spectrum disorders [27, 41, 47].

Oxytocin has also been reported to have various actions in mammals [24, 50, 56, 65], including human-dog bonding [48], anxiolytic effects [49,79], modulation of stress-induced activation of the hypothalamo-pituitary-adrenal axis [20,30,62], modulation of (emotional) memory [45], induction of analgesia [25], termination of food intake [77], suppression of salt appetite [66], an increase in energy consumption [6,67], control of body temperature [33], antiinflammatory actions [11], facilitation of wound healing [26,73], restoration of ovariectomy-induced osteoporosis or obesity [12], protection of cardiomyocytes [28], recovery of age-dependent muscle mass decline [19], protective actions on neuronal damage [71], and control of neuronal development [35, 82].

Oxytocin actions appear to be mediated mainly by the oxytocin receptor [24]. However, oxytocin has also been reported to act on vasopressin receptors and the GABA receptor. Oxytocin can induce analgesia via activation of vasopressin V1A receptor [61]. Social deficits observed in oxytocin receptor-deficient mice are restored by oxytocin application, indicating that oxytocin acts on receptors other than the oxytocin receptor to facilitate social behavior [60]. Oxytocin has also been proposed to act on the GABA receptor containing a delta subunit to block ethanol-induced reduction in locomotion [7].

Here, we review recent findings with focus on the activation and functions of oxytocin neurons in response to somatosensory inputs.

\section{Sensory inputs to oxytocin-synthesizing neurons}

\subsection{Noxious inputs}

Hypothalamic oxytocin neurons receive somatosensory information. Hypothalamic neurosecretory neurons in the supraoptic nucleus, where oxytocin neurons are localized, have been shown to receive nociceptive information from peripheral organs bilaterally [29]. Plasma oxytocin concentrations are increased following noxious stimuli. Nociceptive information is conveyed by $\mathrm{A} \delta$ or $\mathrm{C}$ fibers to dorsal horn neurons, which project ascending fibers to the medulla oblongata (such as the ventrolateral medulla, nucleus tractus solitary), lateral parabrachial nucleus, periaqueductal gray, thalamus, and hypothalamus [23,69]. Noxious stimuli activate noradrenergic neurons in the medulla oblongata, facilitate noradrenaline release within the hypothalamus [57] and activate oxytocin neurons in the hypothalamus [53]. Oxytocin release in response to noxious stimuli is impaired by noradrenaline depletion or by an $\alpha 1$ adrenergic receptor antagonist [52]. The medulla oblongata contains A2 noradrenergic and A1 noradrenergic cells. Local application of a noradrenaline neuron-selective neurotoxin into the A1 noradrenergic region of the ventrolateral medulla but not total ablation of the dorsomedial medulla, which contains A2 noradrenergic neurons, impairs noxious stimuli-induced oxytocin release [54]. All these findings suggest that noxious stimuli activate hypothalamic oxytocin neurons via an activation of medullary A1 noradrenaline neurons projecting to the hypothalamus (Fig. 1).

There are direct projections from the spinal cord to the hypothalamus, including the paraventricular nucleus [14, 23]. Nociceptive afferents also project to the periaqueductal gray matter or parabrachial nucleus [69], from where some neurons project to the hypothalamic paraventricular nucleus [30]. The roles of these projections in sensory transmission to oxytocin neurons in the hypothalamus remain to be clarified.

Not only noxious stimuli but also stimuli previously paired with noxious stimuli, conditioned fear stimuli, activate noradrenergic neurons in the medulla oblongata and oxytocin neurons in the hypothalamus [56]. Hypothalamusprojecting medullary noradrenergic neurons that are activated in response to conditioned fear stimuli are suggested to co-express prolactin releasing peptide (PrRP) and are mainly located in the A2 region of the nucleus tractus solitaries $[52,56,83]$. PrRP is expressed mainly in the A2 noradrenergic neurons, modestly in the A1 noradrenergic neurons and slightly in the dorsomedial hypothalamus $[16,55]$. Although conditioned fear stimuli activate PrRP neurons located in these three regions, the majority of the hypothalamus-projecting PrRP neurons which are activated by conditioned fear stimuli are found in the A2 region [84]. Conditioned fear stimuli-induced activation of oxytocin neurons in the hypothalamus is impaired by PrRP deficiency [80] and by local destruction of noradrenergic projections to the hypothalamus [83]. All of these findings suggest that conditioned fear stimuli activate hypothalamic oxytocin neurons via activation of the medullary A2 PrRP/noradrenaline neurons projecting to the hypothalamus. The upstream region of the A2 PrRP/noradrenaline neurons has been shown to be the medial amygdala [80].

Physiological roles of oxytocin released in response to noxious stimuli or conditioned fear stimuli remain to be clarified. Oxytocin has analgesic [61] or anti-fear [36] actions, consistent with a view that oxytocin attenuates noxious or conditioned fear responses and contributes to the prevention of overreactions of the body in response to noxious stimuli or conditioned fear stimuli.

\subsection{Non-noxious inputs}

Hypothalamic oxytocin neurons receive information not only from nociceptive receptors but also from nonnociceptive sensory receptors. 

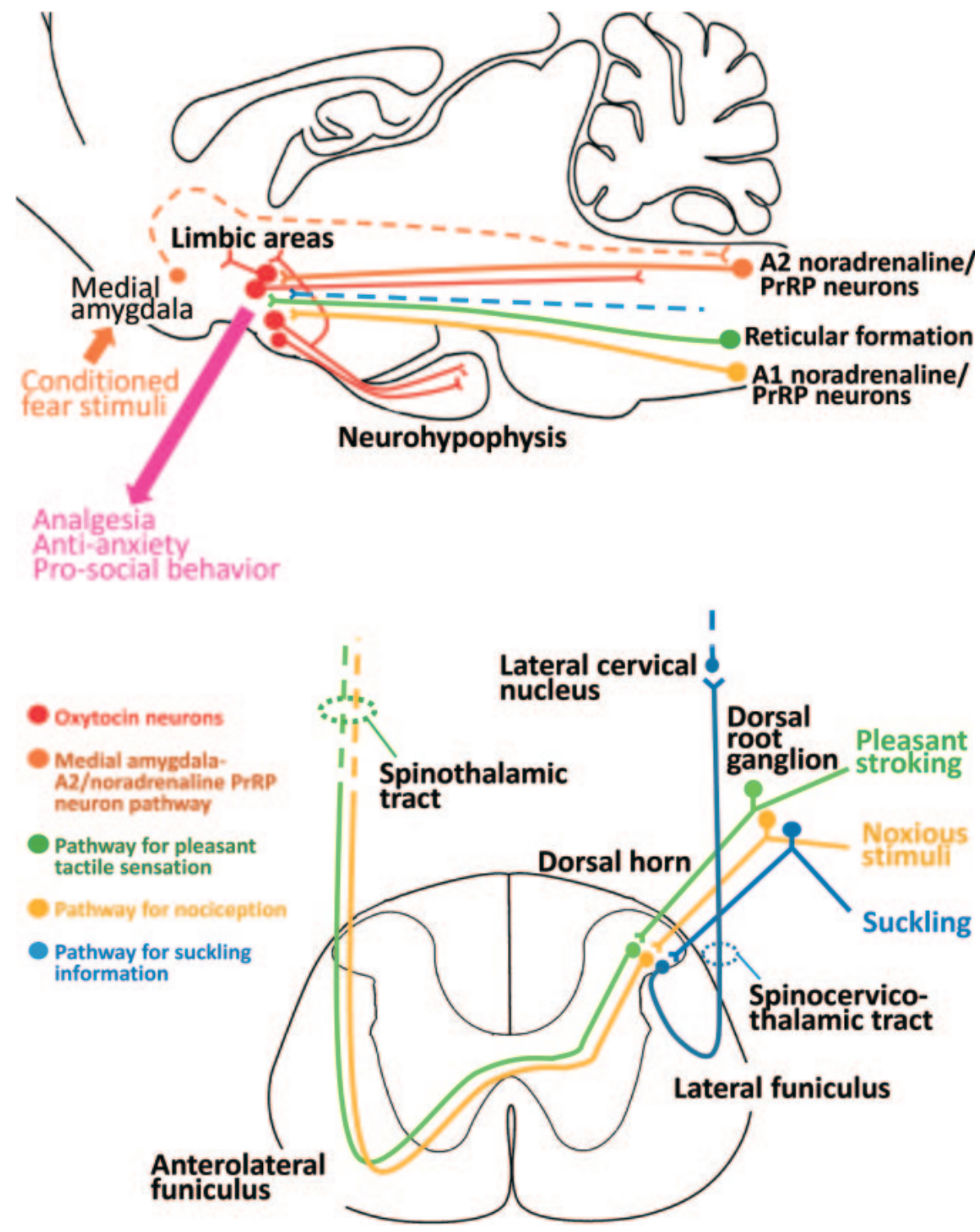

Fig. 1. Noxious or non-noxious inputs to oxytocin-secreting neurons in the hypothalamus. Hypothalamic magnocellular oxytocinsecreting neurosecretory cells project to the neurohypophysis and release oxytocin into the peripheral circulation. Some magnocellular oxytocin neurons send also axonal collaterals to the limbic areas. Oxytocin neurons in the parvocellular region of the hypothalamic paraventricular nucleus project to the limbic areas or to the brainstem. Hypothalamic oxytocin neurons receive inputs from low-threshold mechanoreceptors for pleasant touch via the spinoreticular or spinothalamic tract, from nociceptors via the spinoreticular or spinothalamic tract, and from sensory receptors for suckling via the spinocervicothalamic tract.

\subsubsection{Suckling inputs}

In lactating females, activation of somatosensory receptors by infant suckling stimulates oxytocin-synthesizing neurosecretory neurons in the hypothalamus. Oxytocin released into the blood stream contracts myoepithelial cells surrounding the mammary alveoli and induces milk ejection. Suckling stimuli induce burst firing of oxytocin neurons. The burst firing of oxytocin neurons is synchronized bilaterally among the whole paraventricular and supraoptic nuclei, which is caused by bilateral and intrahypothalamic communications [8].

Massaging or licking of the nipple activates ipsilateral dorsal horn neurons of the spinal cord via C-type afferent fibers derived from the skin around the nipple. Studies with lesions and stimulation have shown that the sensory information from the dorsal horn ascends within the ipsilateral lateral funiculus of the spinal cord, relaying in the lateral cervical nucleus in the cervical segment of the cord, indicating the involvement of the spinocervicothalamic tract. The dorsal column and spinothalamic pathways may not be important for the milk-ejection reflex, since sections of these pathways do not block the milk-ejection reflex. The afferents conveying suckling information from the lateral cervical nucleus cross the midline in the lower brainstem, project to the mesencephalic lateral tegmentum and, after synaptic relays such as in the zona incerta and in the field of Forel, finally reach hypothalamic oxytocin neurons [75]. Involvement of noradrenergic pathways from the medulla oblongata to the hypothalamus has also been suggested in the control of oxytocin release during suckling [75]. 
Not only suckling stimuli but also visual or auditory stimuli previously associated with suckling have been suggested to trigger milk ejection. The sight or sound of the infant facilitates or triggers the reflex in rats, sheep, and cows $[15,21,58]$.

\subsubsection{Sexual sensory inputs}

Oxytocin-synthesizing neurons in the hypothalamus have been shown to be activated during sexual behavior [75]. Plasma oxytocin concentrations are increased at ejaculation and orgasm. In the pre-copulatory phase, plasma oxytocin concentrations start rising, suggesting sexual arousal or sensory inputs as well as vaginocervical stimulation by intromissions activate oxytocin neurons. Tactile stimulation of the penis activates oxytocin neurons in the hypothalamus [78]. Centrally and peripherally released oxytocin plays a role in ejaculation in males, in lordosis in females, and in pair bond formation $[32,72]$.

\subsubsection{Non-sexual sensory inputs}

Tactile stimuli that are not apparently related to reproductive behaviors have also been shown to increase plasma oxytocin concentrations [64,70]. Mutual contact and grooming are associated with increased urinary oxytocin concentrations in female tamarins [63]. In chimpanzees, urinary oxytocin concentrations increase following grooming [13]. In humans, skin-to-skin contact with the baby and the massage-like hand movements by the baby induce oxytocin release in the mother [44]. Recently, we found in rats that non-noxious stroking stimuli that induce emission of 50-kHz ultrasonic vocalization, an index of a positive emotion in rats, activate hypothalamic oxytocin neurons and increase plasma oxytocin concentrations, suggesting that pleasant touch stimuli activate hypothalamic oxytocin neurons [51].

Innocous tactile stimuli activate low-threshold mechanoreceptors of cutaneous sensory neurons. The touch information is conveyed via the large-diameter fast-conducting myelinated $\mathrm{A} \beta$ afferents or small-diameter slowconducting unmyelinated $\mathrm{C}$ fibers. The $\mathrm{A} \beta$ fibers mediate a discriminative touch sense of the glabrous or hairy skin, while the unmyelinated $C$ fibers mediate a sense of affective touch of the hairy skin $[1,46,85]$. $C$ fibers with lowthreshold mechanoreceptors are lacking in glabrous skin. Affective touch sense is induced by gentle stroking with an appropriate velocity. The relationship between stroking velocity and firing rate of C fibers shows an inverted U-shape. Similarly, the relationship between stroking velocity and pleasure sense shows an inverted U-shape. Brushing at a speed of $1-10 \mathrm{~cm} / \mathrm{s}$, which induces a pleasant sensation, activates $\mathrm{C}$ tactile fibers most effectively. Brushing at a lower or higher speed is less effective. In contrast, firing rates in myelinated $\mathrm{A} \beta$ fibers in response to stroking increase as the stroking velocity increases. However, $\mathrm{A} \beta$ afferents may also contribute to affective feeling, since gentle touch on the palm, where $\mathrm{C}$ tactile fibers are lacking, can cause a pleasant sensation [38].

There appear to be, at least, two subtypes of $\mathrm{C}$ fibers with low-threshold mechanoreceptors that contribute to pleasant touch: first, neurons that express vesicular glutamate transporter, tyrosine hydroxylase [40], a chemokine-like protein TAFA4 and the Runx1-dependent transcription factor Zfp521 [42,43], and second, neurons that express the Masrelated G-protein-coupled receptor MrgprB4 [74].

C fibers conveying low-threshold mechanoreceptor inputs project to lamina I neurons of the spinal dorsal horn. The dorsal horn neurons project to the contralateral parabrachial nucleus [3]. Clinical observations that surgical cutting of the anterolateral spinothalamic tract for treatment of intractable pain impairs the sense of affective touch suggest that the anterolateral spinothalamic pathway signals both affective touch and nociception [46]. Roles of the spinocervicothalamic pathway remain to be clarified. Detailed studies with animal experiments concerning neural pathways should be performed.

Gentle stroking activates somatosensory S1 and S2 cortices and also the posterior insular cortex, posterior superior temporal sulcus, medial prefrontal cortex, dorsal anterior cingulate cortex, and medial orbitofrontal cortex, where affective or social processing is performed [46].

Gentle touch reduces anxiety and decreases pain sensation and has pro-social actions. Affective touches also influence the development of neural connections controlling social behavior [31,46,70]. Oxytocin has been suggested to have similar actions. It is thus tempting to speculate that oxytocin mediates social or affective actions of gentle touch.

\section{Conclusion}

Noxious stimuli activate dorsal horn neurons via $\mathrm{A} \delta$ and $\mathrm{C}$ fibers. The nociceptive information ascends in the contralateral spinothalamic tract and enters the hypothalamus and stimulates oxytocin neurons via activation of brainstem reticular formation including noradrenergic neurons in the medulla oblongata. On the other hand, affective touch activates dorsal horn neurons via $\mathrm{C}$ fibers expressing VGLUT3, tyrosine hydroxylase and TAFA4 or MrgprB4 and stimulates oxytocin neurons. Oxytocin induces anxiolytic and analgesic actions and facilitates pro-social behaviors. Thus, oxytocin may attenuate actions of noxious stimuli and mediate prosocial, anxiolytic or developmental actions by affective touch.

Oxytocin application has been reported to induce various actions including pro-social [76], metabolic or anti-ageing effects and has drawn much attention. However, some actions of oxytocin application are controversial and the 
mechanisms underlying the majority of oxytocin actions remain to be clarified $[39,81]$. In conclusion, somatosensory stimuli activate oxytocin neurons in the brain and thus affect physical or psychological health.

\section{Acknowledgements}

This work was supported in part by grants from the Japan Society for the Promotion of Science (24120517, 25118008, 26293049 and 15K15042 to T.O., 15K18978 to S.O., 26460322 to Y.T., and 26460321 to M.Y.) and by the MEXT (Ministry of Education, Culture, Sports, Science and Technology of Japan)-Supported Program for the Strategic Research Foundation at Private Universities.

Disclosure of Summary: The authors have nothing to disclose.

\section{REFERENCES}

[1] Abraira VE, Ginty DD (2013) The sensory neurons of touch. Neuron 79: 618-639.

[2] Aguilera G, Liu Y (2012) The molecular physiology of CRH neurons. Front Neuroendocrinol 33: 67-84.

[3] Andrew D (2010) Quantitative characterization of low-threshold mechanoreceptor inputs to lamina I spinoparabrachial neurons in the rat. J Physiol 588(Pt 1): 117-124.

[4] Beets I, Janssen T, Meelkop E, Temmerman L, Suetens N, Rademakers S, Jansen G, Schoofs L (2012) Vasopressin/oxytocinrelated signaling regulates gustatory associative learning in C. elegans. Science 338: 543-545.

[5] Beets I, Temmerman L, Janssen T, Schoofs L (2013) Ancient neuromodulation by vasopressin/oxytocin-related peptides. Worm 2: e24246.

[6] Blevins JE, Baskin DG (2015) Translational and therapeutic potential of oxytocin as an anti-obesity strategy: Insights from rodents, nonhuman primates and humans. Physiol Behav in press.

[7] Bowen MT, Peters ST, Absalom N, Chebib M, Neumann ID, McGregor IS (2015) Oxytocin prevents ethanol actions at $\delta$ subunit-containing GABAA receptors and attenuates ethanol-induced motor impairment in rats. Proc Natl Acad Sci U S A 112: 3104-3109.

[8] Brown CH, Bains JS, Ludwig M, Stern JE (2013) Physiological regulation of magnocellular neurosecretory cell activity: integration of intrinsic, local and afferent mechanisms. J Neuroendocrinol 25: 678-710.

[9] Cardoso C, Kingdon D, Ellenbogen MA (2014) A meta-analytic review of the impact of intranasal oxytocin administration on cortisol concentrations during laboratory tasks: moderation by method and mental health. Psychoneuroendocrinology 49: $161-170$.

[10] Carter CS (2014) Oxytocin pathways and the evolution of human behavior. Annu Rev Psychol 65: 17-39.

[11] Clodi M, Vila G, Geyeregger R, Riedl M, Stulnig TM, Struck J, Luger TA, Luger A (2008) Oxytocin alleviates the neuroendocrine and cytokine response to bacterial endotoxin in healthy men. Am J Physiol Endocrinol Metab 295: E686E691.

[12] Colaianni G, Sun L, Zaidi M, Zallone A (2015) The "love hormone" oxytocin regulates the loss and gain of the fat-bone relationship. Front Endocrinol (Lausanne) 6: 79.

[13] Crockford C, Wittig RM, Langergraber K, Ziegler TE, Zuberbühler K, Deschner T (2013) Urinary oxytocin and social bonding in related and unrelated wild chimpanzees. Proc Biol Sci 280: 20122765.

[14] Dado RJ, Katter JT, Giesler GJ Jr (1994) Spinothalamic and spinohypothalamic tract neurons in the cervical enlargement of rats. I. Locations of antidromically identified axons in the thalamus and hypothalamus. J Neurophysiol 71: 959-980.

[15] Deis RP (1968) The effect of an exteroceptive stimulus on milk ejection in lactating rats. J Physiol 197: 37-46.

[16] Dodd GT, Luckman SM (2013) Physiological Roles of GPR10 and PrRP Signaling. Front Endocrinol (Lausanne) 4: 20.

[17] Dölen G, Darvishzadeh A, Huang KW, Malenka RC (2013) Social reward requires coordinated activity of nucleus accumbens oxytocin and serotonin. Nature 501: 179-184.

[18] Donaldson ZR, Young LJ (2008) Oxytocin, vasopressin, and the neurogenetics of sociality. Science 322: 900-904.

[19] Elabd C, Cousin W, Upadhyayula P, Chen RY, Chooljian MS, Li J, Kung S, Jiang KP, Conboy IM (2014) Oxytocin is an agespecific circulating hormone that is necessary for muscle maintenance and regeneration. Nat Commun 5: 4082.

[20] Engelmann M, Landgraf R, Wotjak CT (2004) The hypothalamic-neurohypophysial system regulates the hypothalamicpituitary-adrenal axis under stress: an old concept revisited. Front Neuroendocrinol 25: 132-149.

[21] Fuchs AR, Ayromlooi J, Rasmussen AB (1987) Oxytocin response to conditioned and nonconditioned stimuli in lactating ewes. Biol Reprod 37: 301-305.

[22] Garrison JL, Macosko EZ, Bernstein S, Pokala N, Albrecht DR, Bargmann CI (2012) Oxytocin/vasopressin-related peptides have an ancient role in reproductive behavior. Science 338: 540-543.

[23] Gauriau C, Bernard JF (2004) A comparative reappraisal of projections from the superficial laminae of the dorsal horn in the rat: the forebrain. J Comp Neurol 468: 24-56.

[24] Gimpl G, Fahrenholz F (2001) The oxytocin receptor system: structure, function, and regulation. Physiol Rev 81: 629-683.

[25] González-Hernández A, Rojas-Piloni G, Condés-Lara M (2014) Oxytocin and analgesia: future trends. Trends Pharmacol Sci 35: 549-551.

[26] Gouin JP, Carter CS, Pournajafi-Nazarloo H, Glaser R, Malarkey WB, Loving TJ, Stowell J, Kiecolt-Glaser JK (2010) Marital behavior, oxytocin, vasopressin, and wound healing. Psychoneuroendocrinology 35: 1082-1090.

[27] Guastella AJ, MacLeod C (2012) A critical review of the influence of oxytocin nasal spray on social cognition in humans: evidence and future directions. Horm Behav 61: 410-418.

[28] Gutkowska J, Jankowski M (2012) Oxytocin revisited: its role in cardiovascular regulation. J Neuroendocrinol 24: 599-608.

[29] Hamamura M, Shibuki K, Yagi K (1984) Noxious inputs to supraoptic neurosecretory cells in the rat. Neurosci Res 2: 49-61. 
[30] Hatton GI (1990) Emerging concepts of structure-function dynamics in adult brain: the hypothalamo-neurohypophysial system. Prog Neurobiol 34: 437-504.

[31] Holt-Lunstad J, Birmingham WA, Light KC (2008) Influence of a "warm touch" support enhancement intervention among married couples on ambulatory blood pressure, oxytocin, alpha amylase, and cortisol. Psychosom Med 70: 976-985.

[32] Insel TR (2010) The challenge of translation in social neuroscience: a review of oxytocin, vasopressin, and affiliative behavior. Neuron 65: 768-779.

[33] Kasahara Y, Sato K, Takayanagi Y, Mizukami H, Ozawa K, Hidema S, So KH, Kawada T, Inoue N, Ikeda I, Roh SG, Itoi K, Nishimori K (2013) Oxytocin receptor in the hypothalamus is sufficient to rescue normal thermoregulatory function in male oxytocin receptor knockout mice. Endocrinology 154: 4305-4315.

[34] Kelly A, Goodson JL (2014) Social functions of individual vasopressin-oxytocin cell groups in vertebrates: what do we really know? Front Neuroendocrinol 35: 512-529.

[35] Kenkel WM, Yee JR, Carter CS (2014) Is oxytocin a maternal-foetal signalling molecule at birth? Implications for development. J Neuroendocrinol 26: 739-749.

[36] Knobloch HS, Charlet A, Hoffmann LC, Eliava M, Khrulev S, Cetin AH, Osten P, Schwarz MK, Seeburg PH, Stoop R, Grinevich V (2012) Evoked axonal oxytocin release in the central amygdala attenuates fear response. Neuron 73: 553-566.

[37] Knobloch HS, Grinevich V (2014) Evolution of oxytocin pathways in the brain of vertebrates. Front Behav Neurosci 8: 31.

[38] Krämer HH, Lundblad L, Birklein F, Linde M, Karlsson T, Elam M, Olausson H (2007) Activation of the cortical pain network by soft tactile stimulation after injection of sumatriptan. Pain 133: 72-78.

[39] Leng G, Ludwig M (2015) Intranasal Oxytocin: Myths and Delusions. Biol Psychiatry in press.

[40] Li L, Rutlin M, Abraira VE, Cassidy C, Kus L, Gong S, Jankowski MP, Luo W, Heintz N, Koerber HR, Woodbury CJ, Ginty DD (2011) The functional organization of cutaneous low-threshold mechanosensory neurons. Cell 147: 1615-1627.

[41] LoParo D, Waldman ID (2015) The oxytocin receptor gene (OXTR) is associated with autism spectrum disorder: a metaanalysis. Mol Psychiatry 20: 640-646.

[42] Lou S, Duan B, Vong L, Lowell BB, Ma Q (2013) Runx1 controls terminal morphology and mechanosensitivity of VGLUT3expressing C-mechanoreceptors. J Neurosci 33: 870-882.

[43] Lou S, Pan X, Huang T, Duan B, Yang FC, Yang J, Xiong M, Liu Y, Ma Q (2015) Incoherent feed-forward regulatory loops control segregation of C-mechanoreceptors, nociceptors, and pruriceptors. J Neurosci 35: 5317-5329.

[44] Matthiesen AS, Ransjö-Arvidson AB, Nissen E, Uvnäs-Moberg K (2001) Postpartum maternal oxytocin release by newborns: effects of infant hand massage and sucking. Birth 28: 13-19.

[45] McEwen BB (2004) The roles of vasopressin and oxytocin in memory processing. Adv Pharmacol 50: 1-708.

[46] McGlone F, Wessberg J, Olausson H (2014) Discriminative and affective touch: sensing and feeling. Neuron 82: 737-755.

[47] Meyer-Lindenberg A, Domes G, Kirsch P, Heinrichs M (2011) Oxytocin and vasopressin in the human brain: social neuropeptides for translational medicine. Nat Rev Neurosci 12: 524-538.

[48] Nagasawa M, Mitsui S, En S, Ohtani N, Ohta M, Sakuma Y, Onaka T, Mogi K, Kikusui T (2015) Social evolution. Oxytocingaze positive loop and the coevolution of human-dog bonds. Science 348: 333-336.

[49] Neumann ID, Landgraf R (2012) Balance of brain oxytocin and vasopressin: implications for anxiety, depression, and social behaviors. Trends Neurosci 35: 649-659.

[50] Neumann ID, Slattery DA (2015) Oxytocin in general anxiety and social fear: A translational approach. Biol Psychiatry in press.

[51] Okabe S, Yoshida M, Takayanagi Y, Onaka T (2015) Activation of hypothalamic oxytocin neurons following tactile stimuli in rats. Neurosci Lett 600: 22-27.

[52] Onaka T (2000) Catecholaminergic mechanisms underlying neurohypophysial hormone responses to unconditioned or conditioned aversive stimuli in rats. Exp Physiol 85: 101S-110S.

[53] Onaka T (2004) Neural pathways controlling central and peripheral oxytocin release during stress. J Neuroendocrinol 16: 308-312.

[54] Onaka T, Palmer JR, Yagi K (1996) A selective role of brainstem noradrenergic neurons in oxytocin release from the neurohypophysis following noxious stimuli in the rat. Neurosci Res 25: 67-75.

[55] Onaka T, Takayanagi Y, Leng G. (2010) Metabolic and stress-related roles of prolactin-releasing peptide. Trends Endocrinol Metab 21: 287-293.

[56] Onaka T, Takayanagi Y, Yoshida M (2012) Roles of oxytocin neurones in the control of stress, energy metabolism, and social behaviour. J Neuroendocrinol 24: 587-598.

[57] Onaka T, Yamashita T, Liu X, Honda K, Saito T, Yagi K. (2001) Medullary A1 noradrenergic neurones may mediate oxytocin release after noxious stimuli. Neuroreport 12: 2499-2502.

[58] Peeters G, Stormorken H, Vanschoubroek F (1960) The effect of different stimuli on milk ejection and diuresis in the lactating cow. J Endocrinol 20: 163-172.

[59] Puglia MH, Lillard TS, Morris JP, Connelly JJ (2015) Epigenetic modification of the oxytocin receptor gene influences the perception of anger and fear in the human brain. Proc Natl Acad Sci U S A 112: 3308-3313.

[60] Sala M, Braida D, Lentini D, Busnelli M, Bulgheroni E, Capurro V, Finardi A, Donzelli A, Pattini L, Rubino T, Parolaro D, Nishimori K, Parenti M, Chini B (2011) Pharmacologic rescue of impaired cognitive flexibility, social deficits, increased aggression, and seizure susceptibility in oxytocin receptor null mice: a neurobehavioral model of autism. Biol Psychiatry 69: 875-882.

[61] Schorscher-Petcu A, Sotocinal S, Ciura S, Dupré A, Ritchie J, Sorge RE, Crawley JN, Hu SB, Nishimori K, Young LJ, Tribollet E, Quirion R, Mogil JS (2010) Oxytocin-induced analgesia and scratching are mediated by the vasopressin-1A receptor in the mouse. J Neurosci 30: 8274-8284.

[62] Smith AS, Wang Z (2014) Hypothalamic oxytocin mediates social buffering of the stress response. Biol Psychiatry 76 : 
281-288.

[63] Snowdon CT, Pieper BA, Boe CY, Cronin KA, Kurian AV, Ziegler TE (2010) Variation in oxytocin is related to variation in affiliative behavior in monogamous, pairbonded tamarins. Horm Behav 58: 614-618.

[64] Stock S, Uvnäs-Moberg K (1988) Increased plasma levels of oxytocin in response to afferent electrical stimulation of the sciatic and vagal nerves and in response to touch and pinch in anaesthetized rats. Acta Physiol Scand 132: 29-34.

[65] Stoop R (2014) Neuromodulation by oxytocin and vasopressin in the central nervous system as a basis for their rapid behavioral effects. Curr Opin Neurobiol 29: 187-193.

[66] Stricker EM, Verbalis JG (2004) Inhibition of salt appetite in rats by central oxytocin. Am J Physiol Regul Integr Comp Physiol 287: R487-488.

[67] Takayanagi Y, Kasahara Y, Onaka T, Takahashi N, Kawada T, Nishimori K (2008) Oxytocin receptor-deficient mice developed late-onset obesity. Neuroreport 19: 951-955.

[68] Takayanagi Y, Yoshida M, Bielsky IF, Ross HE, Kawamata M, Onaka T, Yanagisawa T, Kimura T, Matzuk MM, Young LJ, Nishimori K (2005) Pervasive social deficits, but normal parturition, in oxytocin receptor-deficient mice. Proc Natl Acad Sci U S A 102: 16096-16101.

[69] Todd AJ (2010) Neuronal circuitry for pain processing in the dorsal horn. Nat Rev Neurosci 11: 823-836.

[70] Uvnäs-Moberg K, Handlin L, Petersson M (2015) Self-soothing behaviors with particular reference to oxytocin release induced by non-noxious sensory stimulation. Front. Psychol 5: 1529.

[71] Vargas-Martìez F, Uvnäs-Moberg K, Petersson M, Olausson HA, Jiménez-Estrada I (2014) Neuropeptides as neuroprotective agents: Oxytocin a forefront developmental player in the mammalian brain. Prog Neurobiol 123C: 37-78.

[72] Veening JG, de Jong TR, Waldinger MD, Korte SM, Olivier B (2015) The role of oxytocin in male and female reproductive behavior. Eur J Pharmacol 753: 209-228.

[73] Vitalo A, Fricchione J, Casali M, Berdichevsky Y, Hoge EA, Rauch SL, Berthiaume F, Yarmush ML, Benson H, Fricchione GL, Levine JB (2009) Nest making and oxytocin comparably promote wound healing in isolation reared rats. PLoS ONE 4: e5523.

[74] Vrontou S, Wong AM, Rau KK, Koerber HR, Anderson DJ (2013) Genetic identification of C fibres that detect massage-like stroking of hairy skin in vivo. Nature 493: 669-673.

[75] Wakerley JB (2006) Milk ejection and its control. In: Knobil and Neill's physiology of Reproduction (Neill JD, ed $3^{\text {rd }}$ Edition), pp3129-3190. Oxford: Elsevier.

[76] Wigton R, Radua J, Allen P, Averbeck, B., Meyer-Lindenberg A, McGuire P, Shergill SS, Fusar-Poli P (2015) Neurophysiological effects of acute oxytocin administration: systematic review and meta-analysis of placebo-controlled imaging studies. J Psychiatry Neurosci 40: E1-22.

[77] Yamashita M, Takayanagi Y, Yoshida M, Nishimori K, Kusama M, Onaka T (2013) Involvement of prolactin-releasing peptide in the activation of oxytocin neurones in response to food intake. J Neuroendocrinol 25: 455-465.

[78] Yanagimoto M, Honda K, Goto Y, Negoro H (1996) Afferents originating from the dorsal penile nerve excite oxytocin cells in the hypothalamic paraventricular nucleus of the rat. Brain Res 733: 292-296.

[79] Yoshida M, Takayanagi Y, Inoue K, Kimura T, Young LJ, Onaka T, Nishimori K (2009) Evidence that oxytocin exerts anxiolytic effects via oxytocin receptor expressed in serotonergic neurons in mice. J Neurosci 29: 2259-2271.

[80] Yoshida M, Takayanagi Y, Onaka T (2014) The medial amygdala-medullary PrRP-synthesizing neuron pathway mediates neuroendocrine responses to contextual conditioned fear in male rodents. Endocrinology 155: 2996-3004.

[81] Young LJ, Barrett CE (2015) Neuroscience. Can oxytocin treat autism?. Science 347: 825-826.

[82] Zheng JJ, Li SJ, Zhang XD, Miao WY, Zhang D, Yao H, Yu X (2014) Oxytocin mediates early experience-dependent crossmodal plasticity in the sensory cortices. Nat Neurosci 17: 391-399.

[83] Zhu L, Onaka T (2002) Involvement of medullary A2 noradrenergic neurons in the activation of oxytocin neurons after conditioned fear stimuli. Eur J Neurosci 16: 2186-2198.

[84] Zhu LL, Onaka T (2003) Facilitative role of prolactin-releasing peptide neurons in oxytocin cell activation after conditionedfear stimuli. Neuroscience 118: 1045-1053.

[85] Zimmerman A, Bai L, Ginty DD (2014) The gentle touch receptors of mammalian skin. Science 346: 950-954. 